\title{
AN ANALYSIS OF THE COMPLETION OF PHYSIOTHERAPY CLINICAL RECORDS in GAUTENG PROvinCE.
}

\begin{tabular}{|c|c|}
\hline $\begin{array}{l}\text { ABSTRACT: The purpose of this study was to rate the completion of } \\
\text { physiotherapy assessment, treatment and progress records in the Gauteng } \\
\text { province of South Africa. There is a dearth of literature on physiotherapy } \\
\text { patient records, yet it has been demonstrated that clinical records have } \\
\text { significant implications for quality of care, resource allocation, research } \\
\text { and for professional litigation. } \\
\text { A combined retrospective and prospective research design, using a } \\
\text { quality assurance instrument was used to rate the completeness of physio- } \\
\text { therapy records obtained from multiple study sites. Breakdown in clinical }\end{array}$ & $\begin{array}{l}\text { M'KUMBUZI VRP, BSc Honours in } \\
\text { Physiotherapy, UZ'; EALES CJ, PhD'; } \\
\text { STEWART A, MSc Medicine } \\
\text { ' } \\
\text { 'Staff Development Fellow, University of Zimbabwe, } \\
\text { Faculty of Medicine, Rehabilitation Department. } \\
2 \text { Head, School of Therapeutic Sciences, Faculty of } \\
\text { Health Sciences, University of the Witwatersrand. } \\
\text { 3 Senior Lecturer Physiotherapy Department, } \\
\text { School of Therapeutic Sciences, Facully of Health } \\
\text { Sciences, University of the Witwotersrand. }\end{array}$ \\
\hline
\end{tabular}

- areas of care (private and public sectors), - patient conditions (e.g. orthopaedic and surgical)

- patient categories (in and out patients), - section of the record (e.g. demographics, physical examination), and

- providers of care (physiotherapists, physiotherapy assistants and physiotherapy students).

The 644 records analyzed scored a mean overall completion rate of $64 \%$. There was a significant difference observed in overall record completion $(p=0.0004)$ between private and public sector providers. Significant differences were also observed for each section of the record. Factors most associated with a high degree of completion of physiotherapy patient records included; private sector physiotherapy services, use of pre-formatted assessment charts and clinicians' participation in relevant continuing education.

Physiotherapy patient records in Gauteng were found to be incomplete. The implications of this finding in an increasingly competitive global, national, corporate and domestic healthcare arena include; physiotherapy service quality, professional litigation, resource allocation and policy development, as well as professional growth, development and satisfaction with ones' career. Recommendations on how the physiotherapy profession can improve clinical recording from an educational, clinical and managerial perspective are suggested.

KEY WORDS: COMPLETION, CLINICAL PHYSIOTHERAPY RECORDS.

\section{This research article is an extract of part of a research report submitted to the Faculty of Health Sciences, University of the Witwatersrand, Johannesburg, in partial fulfillment of the requirements for the degree Master of Science in Physiotherapy, (August 2001).}

\section{INTRODUCTION \\ Background}

Physiotherapy is both a humane endeavour and a business operation (Bauer 1989). In the case of modern day physiotherapy practice, which includes

\section{CORRESPONDENCE TO:}

VRP M'kumbuzi

University of Zimbabwe, Faculty of Medicine, Rehabilitation Department P.O. Box A 178, Avondale, Harare Zimbabwe

Tel: +263-4-791631 or +263-91-317086

Fax: +263-4-791995 or 724912

Email: rehab@healthnet.zw or vyvpiwai2000@hotmail.com community and primary levels of care and private as well as public sector services, physiotherapy involves collaboration with a number of stakeholders. These are ministries of Health, Education, Welfare and Social Services, non- governmental organizations (NGO's), medical aid companies, the clients' family and caregiver as well as the individual client himself. Physiotherapists are therefore accountable to their clients, to society and to the funding source. This " wide range of accountability indicates a wider range of monitoring indicators in the whole process of continuous and ongoing evaluation of any rehabilitation service" (Myezwa 1997).

In an endeavour to transform the health system in the USA, Haughom (2000) proposed that the solution to the health care crisis lay in taking a lesson from industry and providing a higher quality product more efficiently. The way to accomplish this goal is to "collect better information", and apply it to improve care (Haughom 2000).

\section{Aim of Study}

The aim of this study was to determine the degree of completeness of physiotherapy patient assessment, treatment and progress records.

\section{Motivation and Importance of Study}

This study presumes that physiotherapy patient records are important. However, 
there is a dearth of literature relating to information on physiotherapy patient records. In spite of this situation, hospital records are sent to central statistical and planning offices to review health sector performance and determine resource allocation.

Shrinking health budgets at global, national, corporate and household levels necessitate an evaluation of clinical work. The ultimate purpose of a patient record is to provide the data so that clinical caregivers can make timely and accurate decisions. It is thus generally accepted that an analysis of patient records is one way of demonstrating workload as well as the quality of service. Quality is important in the evaluation of physiotherapy practice, as a professional, organizational, administrative and economic enterprise.

\section{Methodology}

\section{Pilot and Feasibility' Studies}

A pilot study was conducted to determine a reasonable null hypotheses test level for the main study; re-familiarize the researcher with the administration of the QA instrument and validate the demographic questionnaire data instrument.

A three-part feasibility study was conducted to determine the relative proportions of physiotherapy clinicians providing physiotherapy services in selected institutions in a given month and the monthly patient loads. Further, other study variables such as the nature of the physiotherapy record for in and out patients which could affect physiotherapy record completion were investigated in order to design a study procedure for sampling and retrieval.

\section{Conclusion and Recommendations of the Pilot and Feasibility Studies. \\ Study Design}

The pilot and feasibility studies led to the conclusion that an analysis of physiotherapy clinical records in Gauteng province using a retrospective methodology was at the time not entirely feasible. This conclusion was based on the premise that a record analysis would have to take into account the following:
- The different levels of physiotherapy care

- The different physiotherapy service providers, and

- The use of a scientifically sound study design.

The combined prospective and retrospective design was deemed necessary in order to include multiple study sites with similar and dissimilar health information systems, and thus gauge more accurately the record keeping practices across the province.

Secondly research assistants were used to:

- Blind the principal investigator to the identity, training level and work experience of the physiotherapy provider who had written the record, prior to and during the process of rating each physiotherapy record.

- To speed up and make more efficient the data collection process.

\section{Study Objectives}

1. To determine the degree of completion of physiotherapy patient records in Gauteng Province

2. To compare the degree of completion of physiotherapy patient records between those written by public sector physiotherapy providers and records written by private sector physiotherapy providers.

3. To determine sections of physiotherapy records that are complete, and incomplete

4. To determine patient factors associated with a high degree of completion of physiotherapy records

5. To determine assessment chart characteristics associated with a high degree of completion of physiotherapy records.

6. To determine physiotherapy service providers' characteristics associated with a high degree of completion of physiotherapy clinical records.

\section{Study Sites}

A sample of seven physiotherapy service providers was selected in the Gauteng province.
Two hospitals represented public sector physiotherapy providers and were selected because

- They are tertiary levels of care,

- Employ physiotherapists and physiotherapy assistants,

- As teaching hospitals they are used for physiotherapy students' clinical practice and

- Following the feasibility study a method of retrieving in-patient and out-patient records could be designed

Four private physiotherapy practices were randomly selected from providers listed in the Gauteng private practitioners' telephone directory and a fifth practice was a convenient selection, because it had become increasingly difficult to obtain consent from private practitioners. Further, the feasibility study had shown the need to use multiple sites with similar and dissimilar health information systems in order to gauge more accurately the record keeping practices across the province.

\section{Physiotherapy Record Selection}

A sample size calculation determined the need to obtain an overall sample of at least 369 records, and 260 records each from the public sector and private sector, in order to detect a $10 \%$ difference in completeness at the 0.05 level of significance.

All records for patients presenting to physiotherapy in the selected institutions for the first time for the current problem during the month of February 2001 were included in the study sample. In this way, the overall sample yielded would be proportional to the volume of new patients presenting to physiotherapy in each institution, and from each clinical unit and area. The month of February was a convenient selection as it gave sufficient time to audit trail and complete the study within the first half of the year.

\section{Main Study Procedure}

Research assistants conducted the first part of the study. This part included:

- Selection of physiotherapy records using the selection criterion. The 
selection criterion was physiotherapy records of patients who received physiotherapy for the first time for the current problem during February 2001.

- Labeling the service provider as a physiotherapist, physiotherapy assistant or physiotherapy student.

- Recording the demographic details of service providers responsible for writing selected patient records

- Recording patient characteristics of patients whose record had been selected, and

- Recording the chart characteristics of selected patient records.

The second part of the study was to rate the completion of physiotherapy records. The principal investigator did this exclusively to eliminate inter-rater variation.

Various techniques were used to select all records meeting the inclusion criteria, the most important technique was the combination of the prospective and retrospective design in the public sector hospitals, audit trail and peer back tracks. The secretary-receptionist in each practice retrieved patient records. The principal researcher was blinded to the profiles of the provider in two ways:

- Records were first rated, then the physiotherapy providers' details obtained from the secretary,

- The researcher knew none of the physiotherapy providers.

\section{Instrumentation}

\section{The Quality Assurance Instrument}

This QA instrument was used to rate the completeness of physiotherapy assessment, treatment and progress records.

The QA instrument was developed in the Midlands province in Zimbabwe between 1994 and 1999 (Myezwa et al, 2001). The salient features of the QA instrument are percentage ratings on the degree of completion of sections of patient records as shown in Table 1.
The QA instrument was piloted in May 2000 on 35 physiotherapy records from Hospital 2 and adapted for use in this study without modification.

\section{The Demographic Data Instrument}

The demographic data included the characteristics of service providers, such as gender, age, years of training, years of experience and place of work. The instrument also elicited data on the condition of patients assessed, and the character of the assessment charts used. These variables have been found to influence chart completion in the literature. The demographic data chart had also been piloted and a few modifications made.

\section{Data Analysis}

Descriptive statistics were used to summarize the demographic characteristics of the physiotherapy clinicians responsible for writing the patient records sampled and the score and rating of the overall completeness of physiotherapy records

A one sample " $t$ " test was calculated to test the null hypotheses for the overall completion of physiotherapy patient records.

A two-sample "t" test was calculated to test the null hypotheses for the overall completion of physiotherapy records written by private sector providers compared to those written by public sector providers.

Pearsons' correlation test was calculated to determine the level of correlation between the percentage physiotherapy record completion and

a) The percentage rating for the physical examination section of the record (including its objectivity).

b) Age of the physiotherapy service provider

c) Number of years of physiotherapy training and,

d) Number of years of working experience.

Table 1: Percentage Ratings of the QA Measuring Instrument.

\begin{tabular}{|l|l|l|l|l|l|}
\hline $\begin{array}{l}\text { Section of } \\
\text { the record }\end{array}$ & $\begin{array}{l}\text { Demographic } \\
\text { data }\end{array}$ & $\begin{array}{l}\text { History } \\
\text { social, past } \\
\text { and present } \\
\text { medical }\end{array}$ & $\begin{array}{l}\text { Physical } \\
\text { Examination, } \\
\text { findings and } \\
\text { problem list }\end{array}$ & $\begin{array}{l}\text { Treatment } \\
\text { Aims and } \\
\text { Plan }\end{array}$ & $\begin{array}{l}\text { Progress } \\
\text { Note, } \\
\text { discharge } \\
\text { and referral } \\
\text { summary }\end{array}$ \\
\hline$\%$ Rating & 15 & 15 & 50 & 10 & 10 \\
\hline
\end{tabular}

\section{Secondary Analytical Statistics}

The above statistical analyses were done for a total sample of 644 (694 less 50 illegible microfiche records) physiotherapy patient records. Of these, 266 were written by private physiotherapists and public sector physiotherapy providers wrote 428 . Since the sample of records ( $\mathrm{n}=644)$ had been written by only 46 physiotherapy providers, (31 public sector providers and 15 private sector providers), the analysis of 644 records could be interpreted as records written by 644 independent clinicians. However, it was likely that where multiple records written by one clinician had been included in the sample for analysis, these records may in actual fact represent the rating of only one record.

Thus, a second database was generated where each physiotherapy provider was represented only once by his or her mean. All third year and fourth year physiotherapy students were grouped to represent one provider each respectively. This was done for the following reasons:

- Students often share the management of a patient, and

- It was not always possible to identify the student..

The one sample " $t$ " test for overall completion and the two-sample " $t$ " test to compare record completion between the two sectors of physiotherapy care were recalculated using the second database.

Power: The sample size of 31 and 15 was used for public sector and private sector providers respectively. Both sectors had a power in excess of $95 \%$ (public sector $100 \%$, and private sector $99.99 \%$ ) in detecting the observed differences for physiotherapy clinical record completion.

Accuracy: The 95\% confidence limits for the overall completeness of physiotherapy records were calculated to be within $4.4 \%$ of the observed mean.

\section{RESULTS}

\section{Study Sites}

One university teaching hospital (1100 beds in use), a non-teaching general hospital ( 780 beds in use), two big private physiotherapy practices and three small physiotherapy practices in Gauteng province were the study sites selected. 
Table 2: Study Sample.

\begin{tabular}{|l|l|l|l|l|l|l|l|l|}
\hline Institution & $\begin{array}{l}\text { Hospital } \\
1\end{array}$ & $\begin{array}{l}\text { Hospital } \\
2\end{array}$ & $\begin{array}{l}\text { Private } \\
\text { practice 1 }\end{array}$ & $\begin{array}{l}\text { Private } \\
\text { practice 2 }\end{array}$ & $\begin{array}{l}\text { Private } \\
\text { practice 3 }\end{array}$ & $\begin{array}{l}\text { Private } \\
\text { practice 4 }\end{array}$ & $\begin{array}{l}\text { Private } \\
\text { practice 5 }\end{array}$ & $\begin{array}{l}\text { Total } \\
\begin{array}{l}\text { Number of } \\
\text { Records } \\
\text { obtained }\end{array}\end{array} 279$ \\
\hline
\end{tabular}

\section{Physiotherapy Clinical Records}

The number and source of physiotherapy clinical records analysed is shown in Table 2.

A total of 694 physiotherapy records were retrieved from the selected institutions (430 from public hospitals and 264 from private providers). Fifty microfiche film records were excluded from the statistical analysis for completion because the film was poor and physiotherapy records illegible. The results are therefore based on the analysis of 644 physiotherapy records..

\section{Physiotherapy Providers}

Forty-six physiotherapy clinicians wrote the records included in the study; 39 were written by physiotherapists, eight (8) by physiotherapy assistants and 21 were written by third or fourth year physiotherapy students. Most $(n=19)$ of the providers were physiotherapists based in Hospital 1, followed by students from Hospital 2. There were no physiotherapy assistants or physiotherapy students providing services in any of the selected private physiotherapy institutions.

In addition 83 records (12\%) were written by a male clinician and $611(88 \%)$ were written by a female clinician.

The mean age of all physiotherapy service providers was 30.3 years (SD \pm 9.5 ).

Two hundred and sixty-six (38.3\%) were records written by private sector physiotherapists while 428 (61.7\%) were written by public sector physiotherapy providers.

\section{Level of Training}

Various categories of training levels were observed. These ranged from third and fourth year students to two year trained physiotherapy assistants and physiotherapists with postgraduate qua-

Figure 1: Patient Conditions of Selected Records.

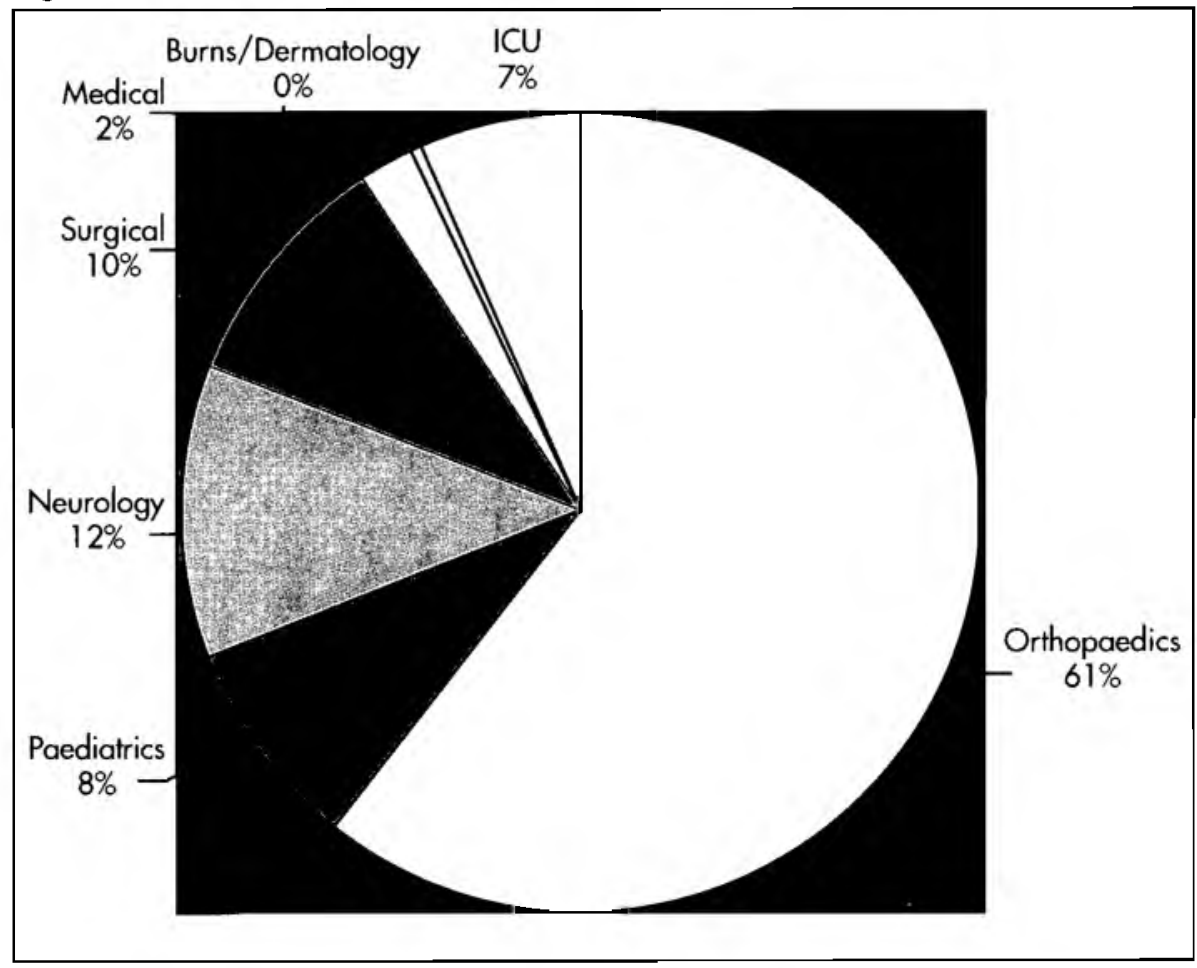

lifications and or several continuing education courses. Most physiotherapy records analyzed were written by physiotherapists with three ${ }^{2}$ or four years basic training only.

\section{Duration of Physiotherapy Work Experience}

Various duration of physiotherapy working experience were observed. Most physiotherapy records that were sampled were written by clinicians with over five years working experience, followed by newly qualified clinicians and physiotherapy students with less than one year working experience.

\section{Characteristics Of Patients \\ Whose Record Was Selected}

Two patient categories were used to classify patients whose record had been selected, thus $352(50.7 \%)$ were records of in-patients while $342(49.3 \%)$ were records of outpatients

The distribution of patient conditions of selected records is shown in Figure 1.

Most physiotherapy patient records selected belonged to patients who had been treated for orthopaedic impairments or dysfunction.

\section{Clinical Physiotherapy Record Formats and Chart Types}

All $(100 \%)$ physiotherapy records selected and analyzed were manually charted i.e. in a written form. In addition $530(76.4 \%)$ were analyzed from a paper format, while 164 (23.6\%) were analyzed from a microfiche film format.

The proportions of the chart types used for physiotherapy records were as follows:

Preformatted chart $=44 \%$, non-preformatted chart $=37 \%$ and partially preformatted chart $=19 \%$.

2) In most parts of the world current physiotherapy training takes four years to complete. The three year degree or diploma was done by the older physiotherapists, very few of whom were included in the study sample from the private sector. 
Table 3a: Record Completion for the Total Study Sample.

\begin{tabular}{|l|l|l|}
\hline $\begin{array}{l}\text { Public Sector Record } \\
\text { Completion }\end{array}$ & $\begin{array}{l}\text { Private Sector Record } \\
\text { Completion }\end{array}$ & $\begin{array}{l}\text { Overall Record } \\
\text { Completion }\end{array}$ \\
\hline $54 \%(S D \pm 15.2)^{3}$ & $78.4 \%(S D \pm 23.5)$ & $64 \%(S D \pm 23.7)$ \\
\hline$N=378$ & $\mathrm{~N}=266$ & $\mathrm{~N}=644$ \\
\hline
\end{tabular}

\section{RECORD COMPLETION}

\section{Completion of Physiotherapy Clinical Records}

The mean overall completion rate for the 644 physiotherapy records is shown in Table 3a. The completion rate for the private sector $(n=266)$, and public sector physiotherapy records $(\mathrm{n}=378)$ is also shown in Table 3a.

The public and private sector mean completion rate was significantly different, with the private sector scoring a higher completion rate $(\mathrm{p}=0.0006)$.

The recalculated mean completion for physiotherapy record completion where each provider is represented by his or her own mean $(\mathrm{n}=46)$ is shown in Table $3 b$.

Table 3b: Record Completion for Sample Expressed as One Mean for Each Provider.

\begin{tabular}{|l|l|l|}
\hline $\begin{array}{l}\text { Public Sector Providers' } \\
\text { Record Completion }\end{array}$ & $\begin{array}{l}\text { Private Sector Providers' } \\
\text { Record Completion }\end{array}$ & $\begin{array}{l}\text { Overall Record } \\
\text { Completion }\end{array}$ \\
\hline $55 \%(S D \pm 12.6)$ & $78.7 \%(S D \pm 6.2)$ & $63.4 \%(S D \pm 15.3)$ \\
\hline $\mathrm{N}=31$ & $\mathrm{~N}=15$ & $\mathrm{~N}=46$ \\
\hline
\end{tabular}

$(p=0.0006)$

The public and private sector mean completion rate remained significantly different with the private sector scoring a higher completion rate, $(\mathrm{p}=0.0006)$.

\section{Record Completion for Physiotherapists in the Public and Private Sectors}

The private physiotherapy practices in this study employed physiotherapists only. Thus a two-sample " $\mathrm{t}$ " test was calculated to compare clinical record completion between physiotherapists only from the public sector and physiotherapists in the private sector. The result shown in Table $3 c$ is based on an analysis that excluded records written by physiotherapy assistants and physiotherapy students in the public sector.

Table 3c: Record Completion for Physiotherapists Only.

\begin{tabular}{|l|l|l|}
\hline $\begin{array}{l}\text { Public Sector Record } \\
\text { Completion by } \\
\text { Physiotherapist Only }\end{array}$ & $\begin{array}{l}\text { Private Sector Record } \\
\text { Completion by } \\
\text { Physiotherapist Only }\end{array}$ & $\begin{array}{l}\text { Overall Record } \\
\text { Completion by } \\
\text { Physiotherapist Only }\end{array}$ \\
\hline $53.9 \%(S D \pm 23.2)$ & $78.4 \%(S D \pm 15.2)$ & $66 \%(S D \pm 23.2)$ \\
\hline $\mathrm{N}=275$ & $\mathrm{~N}=266$ & $\mathrm{~N}=541$ \\
\hline
\end{tabular}

$(p=0.0004)$

The differences in the mean completion between public and private sector physiotherapists remained significant $(\mathrm{p}=0.0004)$.

The completion of physiotherapy records was also significantly different between physiotherapists $(66 \%)$ and physiotherapy assistants (43\%) and between physiotherapy students $(63.83 \%)$ and physiotherapy assistants (43\%) $(\mathrm{p}<0.0001)$.

\section{Record Completion and Related Completion Determinants}

The following associations (Pearsons' correlation test) were calculated:
- completion of physiotherapy records and the physiotherapy providers' age, a weak negative correlation $(r=-0.2382), p=0.1683$ was calculated, indicating that the relationship was not significant.

- completion of physiotherapy records and physiotherapy providers' years of training, a weak positive correlation ( $r=0.2356), p=0.1731$ was calculated, indicating that the relationship was not significant and

- completion of physiotherapy records and physiotherapy providers' years of working experience, a weak negative correlation $(r=-0.2785), p=0.1052$ was calculated, indicating that the relationship was not significant.

\section{Record Completion for Different Chart Types}

Physiotherapy mean record completion for the three chart types was observed to be:

Preformatted chart $=77.3 \%,(\mathrm{SD} \pm 16.6)$, partially pre-formatted $61.4 \%(\mathrm{SD} \pm 19.8)$ and the unformatted chart $46.3 \%$ $(\mathrm{SD} \pm 22.9)$. The mean percentage completions were significantly different between the three chart types $(\mathrm{p}=0.0005)$.

\section{Record Completion for Each Patient Category}

Record completion for in and outpatients is shown in Figure 2. (Refer to next page)

Figure 2: Record Completion for Patient Categories.

The difference in completion for in and outpatient records was significant ( $p<0.0001)$, at the 0.05 level of significance, where outpatient records scored higher completion rates.

\section{Record Completion for Selected Patient Conditions}

Percentage record completion for different patient conditions is shown in Figure 3. (Refer to next page)

Figure 3: Record Completion for Different Patient Conditions

- The difference in record completion was significant between all conditions shown in Fig 3 ( $p<0.0001)$. 


\section{Record Completion for}

\section{Each Section of the Record}

Completion for each section of the record is shown in Figure 4. (Refer to next page)

Figure 4: Record Completion for Each Section of the Record
(Where all values shown in Figure 4 are expressed as \% completion.)

The treatment planning section of physiotherapy records was found to have the lowest completion rate in both the private and public sector, as well as for the overall sample.

Figure 2: Record Completion for Patient Categories.

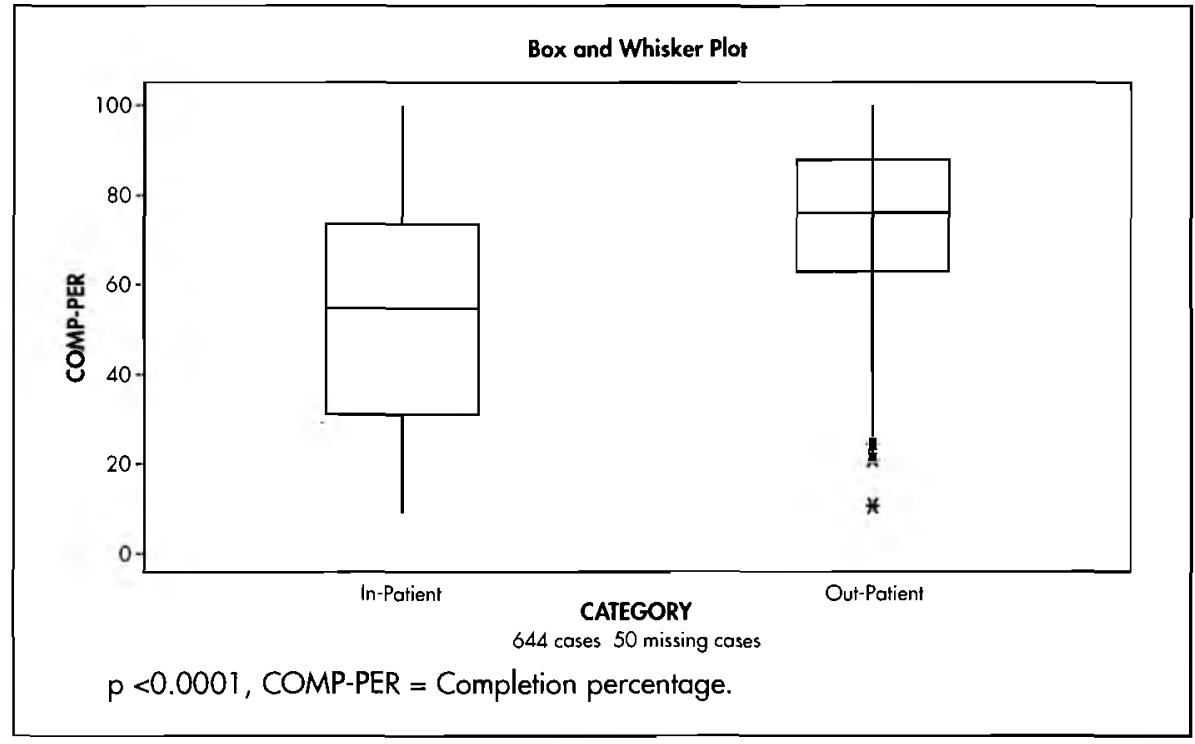

Figure 3: Record Completion for Different Patient Conditions.

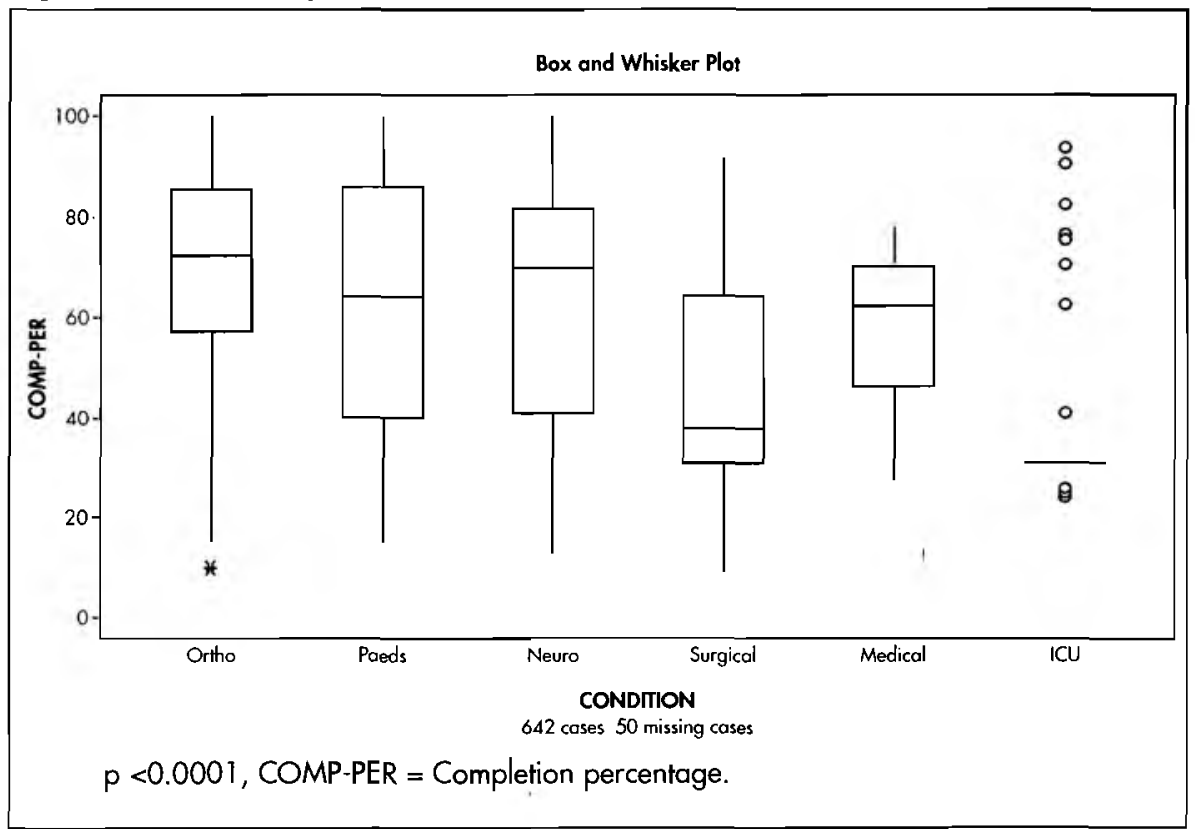

Both private and public sector physiotherapy providers scored the highest completion rate on the demographic section of the clinical record.

Further, in the overall sample $(n=644)$ that was analyzed, $481(69.3 \%)$ records had a hospital or patient identity number, while $213(30.7 \%)$ did not have a hospital or patient identity number.

Overall Clinical Record Completion and Completion of the Physical Examination Section of Physiotherapy Clinical Records

There was a high positive correlation ( $r=0.9$ ) between physiotherapy record completion and completion of the physical examination (including its objectivity), $(\mathrm{p}=0.0004)$.

\section{DISCUSSION}

\section{Physiotherapy Clinical Record Completion}

This is the first known study, which rates the completion and objectivity of physiotherapy patient records.

A mean completion of $64 \%{ }^{4}$ $(\mathrm{SD} \pm 23.7)^{5}$ was found for the physiotherapy assessment treatment and progress record in Gauteng province. However, a distinct dichotomy exists for the overall completion of records between public sector (54\%) and private sector providers $(78.4 \%)$. This difference is also evident for each section of the record.

The factors that seem to facilitate a higher completion of physiotherapy records written by private practitioners include:

- Use of a pre-formatted assessment chart.

- Augmentation of basic physiotherapy training with continuing education (short courses). In particular, the Orthopaedic Manual Techniques $(\mathrm{OMT})^{6}$ short courses which were done by most private practitioners. Two factors make this course extremely relevant; firstly, the course

4) A second statistical analysis, calculated with each provider represented once by his or her mean $(n=46$; observed mean completion $=63.38 \%$ ), substantiated the first analysis where each record represented itself $(n=644$; observed mean completion $=64 \%$ ). The two means were not significantly different. This observation is attributed to the fact that the variation for record completion within each provider was large. This meant that the dependence of record completion observations was not of significant concern. Secondly, the large sample size is believed to have overcome the design effect of multiple records selected from each provider.

5) The high standard deviation (SD) is indicative of the wide variation in completion scores observed. It is attributed to the many factors which influence record completion. These range from patient characteristics, chart characteristics, individual work ethic and departmental policy and management guidelines.

6) The private providers sampled all have significant OMT bias based practices. 
Figure 4: Record Completion for Each Section of the Recors

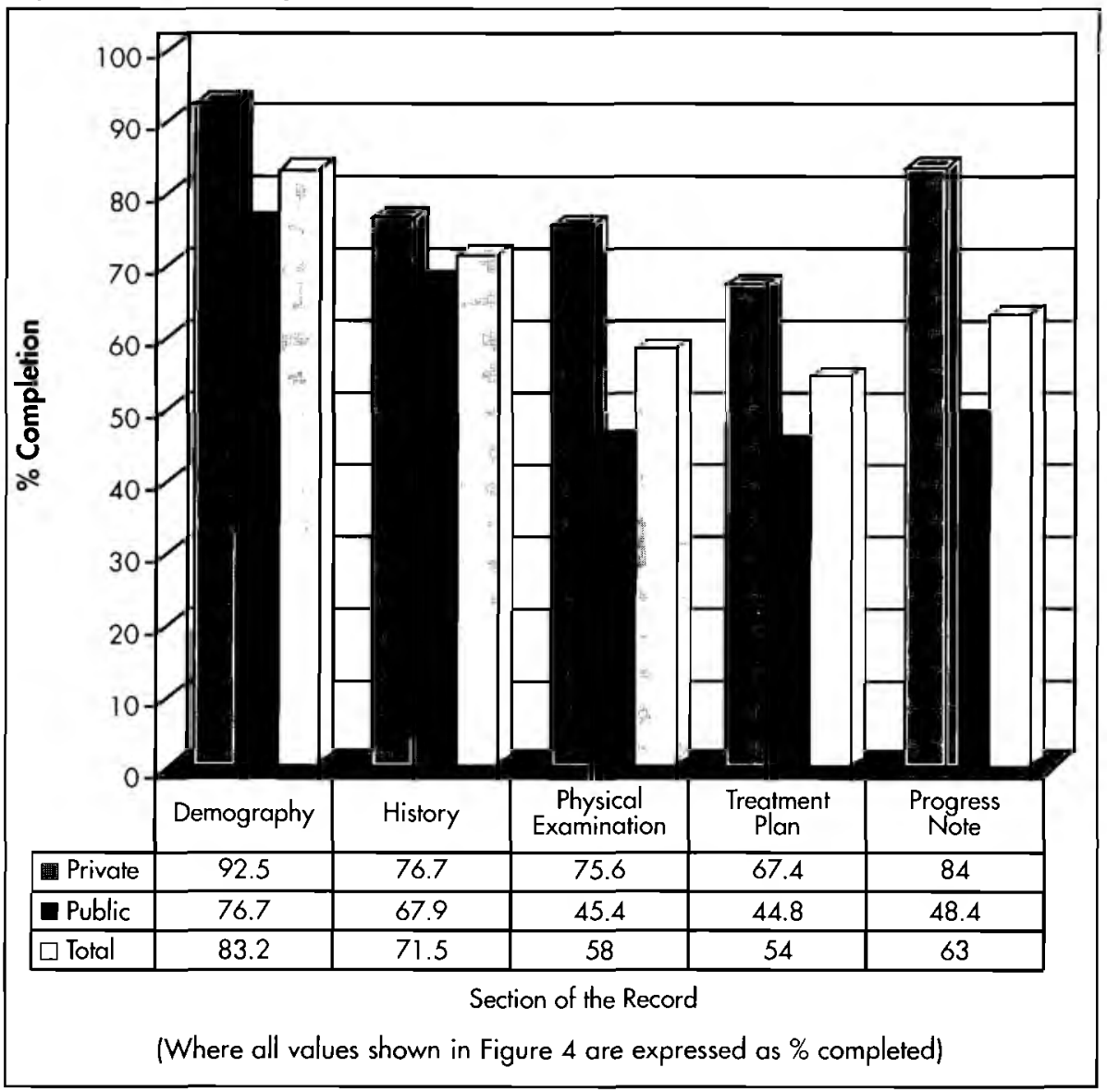

emphasizes appropriate documentation style, and secondly, over $80 \%$ of private practitioners' patients present with orthopaedic complaints. The relevance is demonstrated by the high completion of $79.2 \%$ observed for orthopaedic patient records written by private sector physiotherapists.

- The demographic data section of the record which was filled in by the patient on the first visit.

- The progress note (SOAP) was well written and this too, seems to be attributable to the OMT course.

It is suspected that the high completion rates observed for the demographic and progress note sections were driven by the need to support appropriate billing systems, as this business aspect is critical for private practice survival. This reasoning was also put forward by the Medical Records Institute (1999) as one of the major management and administrative factors driving the need to improve clinical documentation. Furthermore, patient billing in the private sector directly determines individual therapist's remuneration. This incentive does not exist in the public sector as therapists here earn a fixed salary. While it was observed that one of the public sector study sites had instituted the use of time sheets, these were not yet being used to have any bearing on staff salaries.

The weakest section of clinical records written by private practitioners was the treatment planning section $(67.4 \%)$. Many practitioners defended this weakness in this section of physiotherapy clinical records by saying that the process occurs mentally. However, this defense was not acceptable because when different therapists are required to treat the patient, they are not privy to this mental processing when it has not been documented - thereby raising questions as to the continuity, efficacy and cost - effectiveness of physiotherapy care. Further, if an activity is not recorded it is reasonable to assume that it has not been carried out, rather than to assume that the process has occurred mentally.

Another weak area observed for the private sector, was the social history aspect of the history section. Some therapists felt it was not relevant to document in particular the smoking or drinking habits of their predominantly orthopaedic patients. Whatever the case, the history section needs to be relevant as well as comprehensive. The influence of physical, political, social and economic environments on the aetiology and processes of disease and disability is well-documented (Phillips et al 1992; Tarlov 1992). The need to note these risks or aggravating factors in the management and promotion of health is also recognized as necessary if comprehensive care is the service mission. The need to improve the psychosocial component of patient care in physiotherapy has also been documented (M'kumbuzi and Eales 2001).

One may like to argue that private physiotherapy practices also achieved a higher completion in the writing of their patient records because the records obtained from this care area were written exclusively by physiotherapists, i.e. do not employ physiotherapy assistants or train physiotherapy students. However, when record completion was compared between public and private sector physiotherapists (only) a significant difference ( $p=0.0004$ ) was observed between the public sector physiotherapists $(53.9 \%)$ and the private sector physiotherapists (78.4\%). Also, no significant difference in the completion score between records written by all physiotherapists public and private sector physiotherapists combined $(66 \%)$, to those written by physiotherapy students $(63.8 \%)$.

Finally one may also speculate that independent private physiotherapists' records are more complete as they need to obtain as much information as possible because, there is more often than not, no back up teamwork on site from other medical professionals to facilitate clinical decision making.

With regards to records written by public sector physiotherapy clinicians, the demographic and history sections of clinical records (although lower than the private sector) achieved a high completion of $76.7 \%$ and $67.7 \%$ respectively. However, clerks write the demographic section of patient records and the history is written by the admitting doctor on 
the ward or referring doctor from outpatients' clinics. Thus, this achievement cannot be attributed to the recording done by physiotherapy clinicians.

All other sections of physiotherapy patient records written by public sector clinicians scored consistently below $50 \%$. The overall completion of $54 \%$ in the public sector is comparable to the finding of $55 \%$ by Myezwa et al (2001), for public sector rehabilitation records from the Midlands province of Zimbabwe, prior to implementation of a QA programme.

Intensive Care Unit physiotherapy patient records were obtained exclusively from public sector hospitals. A mean completion score of $38.5 \%$ was observed and was the worst score of all the independent variables. This was in spite of having a specific space to enter physiotherapy records on the ICU chart. In many instances the nursing sister was asked to record the statement "Physiotherapy done." Intensive care unit patients often present with co-morbidity, and it is for this reason that one might expect a more analytical assessment or at least the use of the problem oriented medical record, in order to prioritize patients' problems and manage the complicated patient better.

Out-patient records were found to be more complete, contrary to the study by Barrie and Marsh (1992), who found a higher completion for in-patient records. This finding in this study is attributed to the fact that private physiotherapy providers who in any case scored a higher level of record completion from an out-patient population of over $80 \%$, contributed. most of the out-patient records analyzed.

\section{Implications of the Research Findings}

The incompleteness of physiotherapy patient records observed in Gauteng province raise serious concerns. Primarily these are the quality focus of patient care, but also the cost of physiotherapy care for physiotherapy funding agents. Poor patient records may necessitate repetition and duplication of assessment and treatment procedures. These are costly in terms of therapisthours, therapeutic material and financial resources, travel costs for the patient and loss of work time and production capacity for the working patient and his employer.

The use of physiotherapy clinical records from the Gauteng province for resource allocation, research, physiotherapy service review and defense in the case of professional litigation should be done with extreme caution given the critical shortcomings in record completion.

The implication of poorer records found in the public sector relative to the private sector is two-fold:

- Private physiotherapy providers are not obliged to submit their statistics and patients' profiles to the Gauteng health department, and in fact do not. Thus while their records are more complete and the physical examination more objective and more complete, they are not used for policy formulation with regards to health priorities for resource allocation, staff training or other plans for physiotherapy service provision. It would seem that incomplete physiotherapy hospital data, upon which monthly departmental statistics are compiled, would be the only source of information available for use by the Gauteng health department.

- The hospital environment is probably the most important interface between the physiotherapy profession and other medical professions, and from a quantitative perspective between the physiotherapy profession and the public. The display of poor records which may translate to poor patient outcomes poses a serious threat to the respect, growth, development and contribution of physiotherapy to healthcare, in one or all of the following ways:

- Diminished patient satisfaction with the process and outcome of therapy - Diminished recognition of the contribution of physiotherapy to the wider context of health care

- Diminished satisfaction with the profession by the physiotherapy professionals themselves.

\section{Recommendations}

A quality assurance (QA) programme needs to be implemented in all physiotherapy departments. The design of
QA must at least include the following aspects:

- Establish implicit and explicit criteria for measuring quality. Some of the selected criteria may necessitate reviewing current departmental policies and guidelines. In particular to ensure that these do not contradict physiotherapy education principles or the medico-legal obligations and expectations of health professionals.

- Design structures that specify entities such as organization, power relations and coordination of the department and, in particular specification of work procedures.

- Define the processes regarding details of the writing of patient records and their incorporation into a health information system. An area of concern with physiotherapy records is to ensure that the progress note is recorded on a daily basis, and to develop mechanisms to check that this is adhered to. Further to this, methods of retaining raw data after the statistics have been compiled must be developed.

- This study has not demonstrated the link between process and outcomes. The literature illustrates that it is difficult to establish this link, (Kondziolka et al 1989 and Ho et al 1999). However, as beneficence is related to quality (Larabee et al 2001), it is reasonable to expect an inclusion of the relationship between process and outcome in any physiotherapy QA programme.

This broad approach to QA takes into account that criteria, structure, process and outcomes are interrelated, and at various levels each one can affect the completion and therefore quality of physiotherapy record documentation. Therefore QA should in all areas, identify where standards are required; set protocols to set standards; or audit practices where standards exist. The use of peer chart reviews or a review of records and primarily basing judgement of quality on the implicit criteria of expert clinicians are participatory methods that have been used and are recommended in the literature (Myezwa et al 2001).

The pre-formatted chart has been shown in the literature to facilitate chart 
completion (Buckley et al, 1999 and Ho et al, 1999). This too has been the finding in this study. It is recommended that pre-formatted charts be used for physiotherapy records as much as possible. Pre-formatted charts exist in many clinical disciplines as well as in physiotherapy. Further, where pre-formatted charts can be designed for the major conditions seen, this should be done so that all headings are relevant, and so that specific condition considerations are included. This was observed to be in practice in two of the private practices included in this study, where assessment charts were in use for spinal, peripheral, and elbow and shoulder problems. The process of developing these charts will perhaps be arduous, but a comprehensive format should be adapted, as omission of headings will affect chart completion.

Separate physiotherapy clinical records should be used for in-patients in addition to recording in in-patients' bed letters. Often in-patients are discharged from hospital prior to discharge from physiotherapy. The separate physiotherapy records should be used as a continuation record to avoid repetition and duplication of physiotherapy procedures. With time, a clinical data dictionary of terms for communicating physiotherapy processes across medical professions should gradually develop, so as to avoid the global use of terms like "mobilize" in describing interventions done to the hand, back or gait.

The participation in continuing education for physiotherapists is now mandatory for continued registration in some countries including South Africa and Zimbabwe. These courses should encompass an emphasis on appropriate documentation, and the use of the problem oriented medical record should be encouraged as a good method to facilitate chart objectivity and completion. Further, clinicians should be encouraged to focus their continuing education attendance to areas of need as defined by their patient populations.

This study has shown to some extent that poor completion of physiotherapy records is not a result of lack of training on proper documentation practices. It seems, the greatest challenge is to find the determinants of clinically relevant behaviours in physiotherapy, and to manipulate these determinants to bring about the desired change in professional behaviour. There needs to be an uncompromising declaration of professional norms in the standards of physiotherapy assessment, treatment and progress records. A central authority with public and private sector representatives and with sufficient powers to enforce standards is required. These include methods of ensuring data quality such as, record system rules and patient record guidelines, uniformity and consistency in classification systems, standard data sets, and a clinical vocabulary for national and international comparability of data. The professional associations together with the Gauteng health department seem to be best placed to fulfill this role. It may seem militant to expect the physiotherapy professional body to take such a stance, but in view of the implications of poor completion of physiotherapy patient records for the profession, for physiotherapy care and for healthcare cost this is an immediately necessary intervention.

While none of the physiotherapy institutions visited were using IT (at the time of data collection), this study recommends the initiation of IT use in physiotherapy record systems. Many of the advantages which range from improving retrieval, record legibility, decreased recording time and facilitating completion have been described at length in the literature. While initial costs may be overwhelming, only service providers who harness a competitive edge by demonstrating the substantial benefit to the public will survive. To succeed, the resourcing of physiotherapy record keeping systems (incorporated with medical records), including computer networks to raise the quality of care by facilitating smart clinical decisions, has to be a concerted effort on the part of "federal, provincial and national governments in conjunction with the private sector". (Fitzmaurice 1994). This will accelerate health care standards" (Fitzmaurice 1994).

Physiotherapy departments need to use the patient records they write in assessing and planning for physiotherapy services. Only in this way can they test the usefulness of their practices and systems. In addition, physiotherapy providers themselves can devise and test strategies of care that achieve the greatest improvements in physiotherapy care at the lowest cost. When armed with such information, physiotherapy can resist the pressure to accept lower levels of quality because of an expressed inability to afford, whether this pressure comes from the provincial health budget or managed health care financiers in the private or public setting. If the profession cannot resist this pressure it can at least show a truer picture of the losses and gains.

\section{CONCLUSION}

Physiotherapy records in Gauteng province were found to be incomplete, both for the overall completion as well as for each section of the records. This finding compromises the use of physiotherapy patient records for resource allocation, research, physiotherapy service review and defense in cases of professional litigation.

Record completion was significantly better among private physiotherapy providers, however, there is room for much improvement in both sectors. Poor clinical recording of the physiotherapy assessment, treatment and progress note were found to be most evident in the following areas:

- Public sector physiotherapy service

- ICU and surgical patients

- In-patient physiotherapy records taken from public sector physiotherapy providers

- The treatment planning section of physiotherapy records for both private and public sector physiotherapy providers

- The progress note section of physiotherapy records for public sector physiotherapy providers and

- The physical examination sections of physiotherapy clinical records, in particular those written by physiotherapy assistants.

This array of problems points to a three-pronged approach required to improve the quality and usefulness of physiotherapy patient records. These are: 
- The implementation of record systems, standards and regulatory controls through a broad QA programme,

- The inclusion of administration, management and clinical recording in continuing health education and professional development courses and conferences

- The collective and individual pursuit of professional behaviour that is clinically relevant, and uncompromising of the norms and standards of the total practice of physiotherapy.

The commitment and integrity of many stakeholders is required to successfully achieve these goals. These may include provincial governments, physiotherapy funders, physiotherapy training institutions; health information and medical records staff, physiotherapy managers and physiotherapy role models and physiotherapy professional associations. Most important to note however, is that individual therapists need to take proactive steps to improve physiotherapy clinical records.

Health service providers including physiotherapists, have a moral, professional, societal and legal obligation to ensure that patient records are of a high quality. This obligation is captured in the emphasis on the importance of processes rather than the technical practice "in the accountable delivery of a holistic service to people with problems" (Bauer, 1989).

\section{ACKNOWLEDGEMENTS:}

I would like to thank the following persons: Zodwa Kubheka and Naumi Mashalane, for their dedication and thoroughness as research assistants; Hellen Myezwa for her friendly and collegial support; Dr. Piet Bekker for his responsiveness in advising and double checking the statistics in this report and last but not least sincerest gratitude to GTZ - Health Systems Research Eastern and Southern Africa, for bearing the full cost of this study.

\section{REFERENCES}

Barrie JL, Marsh DR 1992 Quality of data in the Manchester orthopaedic database. British Medical Journal 304 (6820); 159-62

Bauer D 1989 Foundations of Physical Rehabilitation - A Management Approach. Ist Edition. Churchill Livingstone

Buckley NA, Whyte IM, Dawson AH, Reith DA 1999 Preformatted admission charts for poisoning admissions facilitate clinical assessment and research. Annals of Emergency Medicine 34(4 Pt 1): 476-482.

Devitt JH, RapanosT, Kurrek M, Cohen MM, Shaw M 1999 The anesthetic record: accuracy and completeness. Canadian Journal of Anaesthetics 46(2): 122-128

Fitzmaurice JM 1994 Health care data standards are required for medically effective use at workstations. International Journal of Biomedical Computers 34(1-4): 331-4

Haughom JL, Transforming U.S. Health Care 2000 The arduous road to value. Top Health Informatics Management 20(3): 1-10

Ho LM, McGhee SM, Hedley AJ, Leong JC1999 The application of a computerized problem oriented medical record and it's impact on patient care. International Journal of Medical Informatics 55(1): 47-59

Kondziolka D, Schwartz ML, Walters BC, McNeil I 1989 The Sunnybrook Neurotrauma Assessment Record: Improving Trauma Data Collection. Journal of Trauma 29(6): 730-5

Larabee JH, Boldreghini S, Elder-Sorrells K, Turner ZM, Wender RG, Hart J 2001 Evaluation of documentation before and after implementation of an information system in an acute care hospital. Computerized Nursing 19(2): 56-65; quiz 66-8

M'kumbuzi VRP, Eales C J 2001. Physiotherapy and Occupational Therapy: training together toward patient care. In Press.

Myezwa HM 1997 The impact of CBR services in Zimbabwe. Asia Pacific Journal 6(1): $7-9$

Myezwa HM, M'kumbuzi VRP, Mhuri F 2001 Quality Assurance in a Rehabilitation Service. South African Journal of Physiotherapy 57 (1): $7-11$
Perlman BB, Schwartz AH, Paris M, Thornton JC, Smith H, Weber R 1982 Psychiatric records: variations based on discipline and patient characteristics, with implications for quality of care. American Journal of Psychiatry 139(9): 1154-7

Phillips DR, Hyma B, Ramesh A 1992 A comparison of the use of traditional and modern medicine on primary health care centres in Tamil Nada. Geo Journal 26(1): 21-30

Tarlov AR 1992 The coming influence of a social sciences perspective on medical education. Academic Medicine 67(11): 724-31

The Medical Records Institute.1999. "Electronic health records trends and usage." http:/www.medrecinst.com/survey/analysis/ results.shtmail (10 March 2001) 